\title{
Letrônica
}

\section{Significados Negociados}

Negotiated Meanings

Aline Sapiezinskas Kras Borges Canani ${ }^{1}$

Graduada em Letras pela UFRGS e Doutora em Antropologia Social pela UnB. Docente do Centro Universitário de Brasília, é tamNúcleo de Estudos em Linguagem e Sociedade do CEAM/UNB e do CET/UNB. Autora de "Como se constrói um artesão", Revista Horizontes Antropológicos, PPGAS/UFRGS, ano 18, n. 38, p. 133-158, jul.-dez. 2012. E-mail: aline.sapiens@gmail.com
RESUMO: 0 presente artigo trata do significado, mais especificamente de negociações de significados, através de uma perspectiva que combina a abordagem etnográfica da antropologia social com a análise do discurso da linguística. A abordagem proposta destaca a noção de interação social, conforme apontada por Goffman (1989) e de contexto, presente em Geertz (1989) e Van Dijk (2011/2012). 0 objeto empírico são dados de pesquisa etnográfica realizada pelo método da observação participante e por meio de entrevistas semiestruturadas com funcionários da Secretaria do Trabalho do Governo do Distrito Federal, em Brasília. As observações revelam dinâmicas de poder inerentes à negociação e à disputa pela imposição do significado em um contexto burocrático de emissão de licenças de trabalho. As categorias de classificação e o método empregado deixam perceber a fluidez do significado face às arbitrariedades inerentes ao processo.

PalaVRaS-CHAVE: Significado; Representação; Contexto; Discurso; Poder.

ABSTRACT: This article proposes a discussion on meaning or rather on meaning negotiations. I intend to combine an ethnographic anthropological approach with the lingüistic discourse analysis. In order to do that, I use the concept of social interaction, as found in Goffman (1986), and context, as defined by Geertz (1989) and Van Dijk (2011/2012). My empirical object is research data obtained through the method of participant observation as well as through semi-structured interviews, conducted among the employees of the Labour Department of the Federal Disctrict Government in Brasilia (Secretaria do Trabalho do Distrito Federal). The observations revealled the dynamics of power within the negotiation process and the struggle to impose meaning in a burocratic context of working licenses emission. The classification cathegories and the method employed allow us to notice the maleability of meaning face to the arbitraryness of meaning attribution in the process.

KEywords: Meaning. Representation; Context: Discourse; Power 


\section{Introdução}

s estudos do significado têm se caracterizado como objeto interdisciplinar, na confluência entre a linguística, a comunicação, a antropologia, a sociologia, a psicologia, entre outras disciplinas. Cada uma delas apresenta suas contribuições específicas e a possibilidade de composição entre as abordagens enriquece grandemente a análise. 0 foco do presente artigo é refletir sobre o significado e, mais especificamente, sobre as negociações de significados, através de uma perspectiva que combina a abordagem etnográfica, da Antropologia Social, com a abordagem da Análise do Discurso, da Linguística. Dentro dessa abordagem, adquirem especial relevo a noção de interação social, conforme apontada por Erving Goffman (1986), e a de contexto, presente tanto em Geertz (1989) quanto em Van Dijk (2011/2012), conforme desenvolvo a seguir. O objeto empírico consiste em dados de pesquisa etnográfica realizada pelo método da observação participante e por meio de entrevistas semiestruturadas, com funcionários da Secretaria do Trabalho do Governo do Distrito Federal, em Brasília, realizadas por mim em 2007 (cf. SAPIEZINSKAS, 2008). As observações revelam as dinâmicas de poder inerentes à negociação e à disputa pela imposição do significado em um contexto burocrático de emissão de licenças de trabalho. Foi empregado o método clássico da pesquisa etnográfica, observação participante no trabalho de campo, que consiste em frequentar o local e acompanhar os atores sociais em suas práticas cotidianas, observando em detalhe seu modo de agir e os procedimentos adotados por eles, incluindo o registro de todas as informações obtidas nos diários de campo. A realização da tarefa contou com entrevistas semiestruturadas dialogadas, que se revelou útil para investigar as categorias culturais presentes no modelo em ação nesse campo e elucidar quaisquer dúvidas que a frequentação e a observação possam ter deixado.
Cabe destacar que a antropologia apresenta como especificidade metodológica, no conjunto das ciências sociais, a de só trabalhar com conceitos na medida em que eles aparecem em campo ou, se trazidos de fora, na medida em que se revelam úteis para lidar com categorias empregadas pelos nativos. 0 modelo tradicional da sociologia, assim, que parte de hipóteses ou de teorias para o campo é invertido ${ }^{1}$. Dessa forma, a apresentação teórica e conceitual que segue é introduzida antes da descrição do campo apenas como expediente didático, uma vez que surge, efetivamente, após a experiência descrita.

A teoria de Simmel (1971(1908)) lançou as sementes de uma corrente teórica conhecida na antropologia como interacionismo simbólico. A obra de Simmel inspirou outros pesquisadores que desenvolveram diferentes aspectos teóricos de sua produção. Entre eles podemos citar Erving Goffman (1986), sobre os rituais de interação, Berger e Luckmann (1985), sobre a construção social da realidade e Herzfeld (1992), sobre a manipulação de categorias de classificação e a interação social conforme influenciada pelos "tipos sociais" (SIMMEL, 1971 [1908]), especialmente no caso da burocracia.

Max Weber foi contemporâneo de Simmel e, segundo Levine (1971), assistiu a diversas conferências de Simmel na Universidade de Berlim, no começo do século passado. Há certas aproximações teóricas entre a noção de “tipo ideal", proposta por Weber (1999), e a noção de "tipos sociais" presente em Simmel (1971 [1908]). Ao norte-americano Clifford Geertz (1989) podemos atribuir o papel de herdeiro de Max Weber. É em Weber (1999), efetivamente, que Geertz encontra a noção de cultura como sendo composta pelas "teias de significados que a própria sociedade teceu", de acordo com

1 Essa é a única forma de evitar que os preconceitos e os valores do antropólogo se imponham sobre os nativos Com isso, a partir do campo, como nota Da Matta "todo antropólogo realiza (ou tenta realizar), nativos. Com isso, a partir do campo, como nota Da Matta, 'todo antropólogo realiza (ou tenta realizar), portanto, o seu próprio 'repensar a antropologia', postura que - como nos revelou explicitament da disciplina" (DA MATTA, 2000: p. 147). 
a formulação clássica do teórico alemão. Continuando a tradição de Weber, a obra de Geertz torna-se referência-chave para a antropologia simbólica ao definir o homem como um animal simbolizante, conceptualizante e pesquisador de significados: "as pessoas usam conceitos da experiência próxima espontaneamente, [...] não reconhecem, a não ser de forma passageira e ocasional, que o que disseram envolve 'conceitos'" (GEERTZ, 1989, p. 89). Ao resgatar a concepção weberiana do homem como um animal "amarrado a teias de significados que ele mesmo teceu", Geertz concentra no conceito de Cultura a chave para a compreensão desses significados. Para ele, os mesmos processos ocorreriam em diversos âmbitos da cultura que se queira tomar como análise. Uma mesma lógica residiria e operaria, assim, tanto na economia quanto na religião ou nas artes, sendo a definição do objeto de análise apenas um dos meios possíveis de se abordar tal sistema de significados.

Tendo em vista que uma artesã não se torna uma artesã apenas porque está empregando uma técnica artesanal, mas porque está inserida num contexto em que ser uma artesã possui um significado social em articulação com outros significados, dos quais ela compartilha, destaca-se a relevância da contextualização das práticas observadas a partir dos significados sociais, conforme proposto por Geertz.

Segundo Erving Goffman (1986), a sociedade estabelece as categorias a partir das quais classifica os indivíduos e também define o conjunto de atributos que os indivíduos têm de preencher para fazer parte delas. As interações sociais seriam baseadas em tais categorias e no conjunto das expectativas dos atores sociais sobre os atributos dos indivíduos que se encaixam nelas. Aplicando a visão de Goffman às estruturas que fundamentam a prática burocrática, restaria ainda observar os usos maleáveis dessas categorias quando executados pelos indivíduos que estão lidando com elas no dia a dia. Com isso, recupera-se o ponto de vista da pragmática, interessada nos significados simbólicos das categorias construídas tal como são atualizadas pelos atores no uso cotidiano. Essa dimensão se revela na fala dos próprios atores sobre como são empregadas as categorias definidas pela instituição, e por isso, os diálogos estão reproduzidos no corpo do artigo.

Os fundamentos epistemológicos da disciplina antropológica nos fornecem uma chave de ingresso nessa dinâmica social, em harmonia com a proposta de abordagem do social na Análise do Discurso, presente tanto em Teun van Dijk (2011) como em Fairclough (1995). O texto é entendido por esses autores como parte dos eventos sociais, recurso de interação de que fazem uso os atores sociais na vida cotidiana, para diversas finalidades, tais como representar aspectos do mundo, relacionar-se com os demais, assim como identificar a si mesmos e aos outros, no exercício dialético da alteridade e reflexividade. Assim, o pressuposto da Análise do Discurso conforme esses autores é de que a linguagem só pode ser compreendida com base em diálogos interdisciplinares, por ser entendida como uma prática social e como instrumento de poder.

Sobre a análise textual, Fairclough afirma que,

o que lhe confere cientificidade é o trabalho explanatório, isto é, de compreensão conjugado com a explanação. Pela compreensão descrevemos e interpretamos propriedades dos textos, e pela explanação investigamos o texto como material empírico à luz de conceitos, de um arcabouço teórico particular (FAIRCLOUGH, 1995, p. 23).

Michael Herzfeld (1992), por sua vez, propõe interessante análise dos significados simbólicos dos usos de categorias de classificação na prática burocrática da administração de uma cidade na Grécia. Esse autor salienta a importância de se observar os usos da retórica para além das categorias de classificação, como condição mesma da possibilidade de negociação entre as formas fixadas em palavras e o seu uso aplicado aos casos concretos: 
"Rhetoric is not simply the pure art of classification. It is the practice of symbolic action - a process in which fixed form is often not only the mask, but even the enabling condition, for labile meaning" (HERZFELD, 1992, p. 69).

O autor define essa manipulação por meio da retórica das categorias de classificação que se apresentam fixas em palavras como a prática da ação simbólica mesma, que garante a possibilidade das manobras no campo simbólico.

Podemos avançar no pensamento de Herzfeld e afirmar que a prática dos atores na manipulação das categorias e formas de classificação da burocracia por meio da manipulação dos significados e da prática da retórica promove a reatualização das categorias em si, uma vez que elas são reificadas pela referência que se faz a elas, sendo continuamente vivificadas e atualizadas, permitindo novas interpretações que venham se juntar a essas no futuro.

Fairclough (1990) chama a atenção para a importância de que a análise do discurso seja realizada de forma situada, ou seja, com o contexto de fala definido, pois entende que o contexto social é fundamental para a compreensão do discurso. Isso fica claro quando ele afirma que discursos são eventos sociais, carregados de sentidos que são observáveis quando se considera o contexto discursivo. Suas análises privilegiam as questões de poder e abuso de poder, nas quais a linguagem é entendida como um instrumento a serviço do poder.

Tal abordagem se coaduna com os meus objetivos de análise ao compreender a linguagem em sua profundidade nas práticas sociais, como forma de agir no mundo, de representar e identificar a si mesmo e aos outros. "Nas práticas sociais a linguagem se manifesta como discurso" (FAIRCLOUGH, 1990, p. 15) "Isso significa que o fluxo de nossa vida diária sempre envolve ação e interação, relações sociais, pessoas (com crenças, valores, atitues, histórias, etc) mundo material e discurso" (FAIRCLOUGH, 2003, p. 25).
Nesse contexto, cabe retomar a definição da antropologia, proposta por Geertz (1989), como uma lente por meio da qual olhamos para o mundo e que nos permite conhecer as diferentes subculturas ou variedades culturais que coabitam o mundo contemporâneo, enriquecendo a apreensão da realidade social observada. Concebida como conjunto de sistemas entrelaçados de signos interpretáveis, a cultura é para Geertz um contexto, algo dentro do qual processos, acontecimentos e instituições sociais podem ser entendidos e descritos com densidade:

O impulso de retirar um sentido da experiência, de dar-lhe forma e ordem, é evidentemente tão real e tão premente como as necessidades biológicas mais familiares. Sendo assim, parece desnecessário continuar a interpretar as atividades simbólicas - religião, arte, ideologia - como nada mais do que expressões um pouco disfarçadas de algo diferente do que são: tentativas de fornecer orientação a um organismo que não pode viver num mundo que ele é incapaz de compreender (GEERTZ, 1989, p. 158).

Geertz sustenta ainda que, para entendermos as concepções alheias, é necessário deixar de lado, em suspenso, nossa própria concepção e buscar ver as experiências dos outros com relação a sua própria concepção do eu, buscando entender como esse sujeito se insere na teia de significações que constitui o seu universo cultural.

Compartilhando dessa noção de contexto como elemento fundamental para a compreensão e análise dos sentidos do discurso, temos em Van Dijk que "os contextos são construtos (inter)subjetivos concebidos passo a passo e atualizados na interação pelos participantes enquanto membros de grupos e comunidades" (VAN DIJK, 2011, p. 11).

Com referência ao trabalho de campo como método de trabalho na disciplina antropológica, e aplicável aos estudos do discurso, o que Geertz propõe é uma "descrição densa" do trabalho de campo, uma etnografia realizada com intenso trabalho de análise e interpretação da cultura 
observada. Nesse caso, a cultura seria interpretada semelhantemente a um texto, em que o leitor, no caso o antropólogo, teria a tarefa de completar as lacunas de sentido deixadas pelo autor durante o processo de escrita. Assim como uma obra literária, a cultura observada pode receber diversas interpretações, variando conforme são diferentes os seus leitores/analistas.

A partir da ideia de "teias de significado" e da proposta de uma abordagem mais interpretativa e semiótica da cultura, encaixam-se as teorias comunicacionais, e voltadas para investigações do campo simbólico, tais como as de Mary Douglas $(1986,1996)$ e Teun Van Dijk (2011). Essa abordagem interacionista simbólica, desde Simmel, compartilha com Geertz e Van Dijk o pressuposto teórico de que o significado se revela na observação do contexto em que ocorre a interação.

De acordo com Van Dijk, a análise do discurso desenvolve-se nas últimas décadas "desde um estudo formal das sentenças, discursos, atos de fala, interação, eventos comunicativos ou processamento mental, para abordagens mais sensíveis num sentido social ou contextual“ (VAN DIJK, 2012, p. 30).

Esse autor entende o contexto como "constructos subjetivos dos participantes, ou definições subjetivas das situações interacionais ou comunicativas" (VAN DIJK, 2012, p. 34). Ele destaca que as situações sociais influenciam o discurso através das interpretações (inter)subjetivas que os participantes constroem. Na definição do autor, os contextos são constructos únicos, que condicionam maneiras únicas de utilizar a linguagem: "Os contextos são um tipo específico de modelo da experiência. Se os contextos são modelos mentais que representam situações comunicativas, eles são também um tipo especial dos modelos mentais que as pessoas constroem passo a passo das situações e entornos de suas vidas diárias, modelos esses que podemos chamar de "modelos da experiência" (VAN DIJK, 2012, p. 34).
Van Dijk afirma ainda que tais modelos dinâmicos controlam toda a percepção e interação em progresso e consistem em categorias básicas.

A partir dessa breve introdução teórica, observa-se que o contexto em que ocorre a interação é considerado fundamental para o entendimento dos significados que estão presentes na interação e nos discursos dos atores sociais. Dar conta dessas diferentes dimensões do conhecimento presentes na abordagem da análise do discurso levando em conta o contexto social de produção de significados exigirá que sejam empregados recursos teóricos multidisciplinares, e desse compartilhamento saem ganhando tanto a linguística quanto a teoria social, uma vez que as teorias, postas em diálogo, surgem revigoradas.

\section{Negociação de significados}

A disputa pelo significado se dá em meio a uma batalha de classificação que inicia quando a artesã busca o reconhecimento de sua situação profissional pelo Estado, ao inscrever-se oficialmente como artesã. O ingresso no campo formal do artesanato demanda a obtenção de um registro de artesão, comprovado por meio da "carteirinha de artesão", elaborada pela Gerência de Artesanato da Secretaria do Trabalho do Governo do Distrito Federal. Um dos primeiros passos no ingresso do artesão nesse campo passa pela etapa burocrática de registro. Como toda burocracia, trata-se de formas de classificação e ordenamento da atividade, e também da definição da atividade artesanal do ponto de vista do Estado.

Ana Maria França, a responsável técnica pelo fomento ao artesanato em Brasília, me recebeu para uma entrevista e explicou o funcionamento da Gerência de Artesanato, subordinada à Secretaria do Trabalho do Governo do Distrito Federal (GDF). Segundo ela, "Aqui, basicamente, a gente registra, faz o cadastro do artesão. 0 artesão, para ter a sua cartei- 
rinha, ele tem que estar registrado aqui. Cadastrado aqui" (SAPIEZINSKAS, 2008, p. 228) ${ }^{2}$.

Sobre as vantagens que podem ser obtidas pelo artesão que tiver o registro na Secretaria do Trabalho do GDF, Ana Maria França explicou que, além de oportunidades de participação em feiras, existiria ainda a autorização para emissão de nota fiscal e a isenção de impostos. Na sua avaliação, os artesãos teriam oportunidades futuras, podendo ser convidados para exposições e para a "vitrine do artesão", que se localiza no CONIC, um centro comercial de grande circulação de pessoas, localizado em uma região central de Brasília.

Antigamente ficava pronta no mesmo dia. Mas o que a gente percebeu, foi percebido pela direção, é que havia necessidade que houvesse uma palestra, para abordar e oferecer os próprios serviços que tem na Secretaria, um próprio entendimento, então ultimamente ele está sendo entregue pelo Secretário. (...) E onde eles dão as informações sobre a Secretaria, sobre o Centro de Comercialização, que a Secretaria dispõe (SAPIEZINSKAS, 2008, p. 228).

Ana Maria explicou que foi mudado o procedimento de entrega das carteirinhas de artesão para criar um evento de caráter pedagógico que pudesse oportunizar um maior contato com as práticas e políticas da instituição, levando essas informações aos participantes do programa.

Essa dinâmica leva em conta o ponto de vista da autoridade que representa o Estado na definição de quem é e quem não é artesão, e que passa também pela definição do tipo de material considerado apropriado para a atividade artesanal. Conforme me explicou Ana Maria França:

A técnica que você utiliza é importantíssima, pois na medida que você utiliza, sabe pegar uma técnica e utilizar com a matéria prima adequada para poder ter um produto aceitável no mercado de trabalho, isso para mim é artesanato (SAPIEZINSKAS, 2008, p. 223)

\footnotetext{
As citações referem-se à página da tese de Doutorado da autora onde o diálogo, registrado nos cadernos de campo, é transcrito. Para uma contextualização maior dos diálogos sugere-se a leitura da tese.
}

Lidando diretamente com a burocracia de registro, a funcionária destacou a importância da técnica e da matéria prima adequada. Ambos os termos: "técnica" e "matéria prima" são recorrentes nos discursos, e ela os empregou para uma definição geral do sentido de "Artesanato":

Quando você pega uma matéria prima que não é tão aceitada naquela técnica e você consegue fazer, obter um produto totalmente diferente, você está inovando. A criatividade ali, a originalidade está ali, então, quer dizer, para mim teria que definir, eles começam já discutindo a matéria prima, se você faz (SAPIEZINSKAS, 2008, p. 223).

Observa-se a recorrência dos termos técnica e matéria-prima, e somado a isso outros critérios referentes ao campo semântico da criação ou da arte aparecem: inovação, criatividade e originalidade. Surgem no discurso essas três categorias a serem levadas em conta na definição da pertinência ou não da atividade artesanal proposta pelo candidato a uma carteira profissional. Ela explicou:

A Secretaria do Trabalho só cadastra bijuteria natural. Mas o que a gente vê com o mercado de trabalho é que são aqueles negócios coloridos, bem rosinha, miçanga, aquelas resinas, aqueles negócios, essa não é uma matéria prima aceitável? A Ana Maria acha que é. Mas quando eu vou fazer um cadastramento eu coloco, se você for chamado para uma exposição da secretaria o seu produto tem que ser o mais natural possível, para não fugir do artesanato, por que é uma luta que se tem é que não se fuja. Então, eu acho importantíssimo, quando for definir o artesanato, que veja essa parte da matéria prima (SAPIEZINSKAS, 2008, p. 223)

Ao mesmo tempo em que procura elucidar a lógica ou a coerência dos critérios estabelecidos pela Gerência de Artesanato, a funcionária pergunta a si mesma se miçangas plásticas ou de resina não seriam matéria prima aceitável, e, imediatamente, responde: “a Ana Maria acha que é", afastando de si a responsabilidade por uma definição que ela possivelmente perceba 
como arbitrária. Ao fazer essa ressalva, ela se distancia da posição de poder decisório a respeito do que pertence a categoria de produto artesanal, até o presente construído como "técnica + matéria prima". Na sua explicação, ela toma partido do artesão, quando diz "coloco, se você for chamado para uma exposição da secretaria..." Ana Maria está buscando orientar o olhar desse cidadão para que ele se dê conta das regras estritas que irão controlar a sua possibilidade de participação nas atividades comerciais organizadas pelo governo local.

Então, se você tem uma matéria prima "x", aplica uma técnica nela e faz um produto, com acabamento, com criatividade, aí outros conceitos, eu posso considerar isso como artesanato atualmente. Não só o indígena, o indígena é bem natural, você não vai ter que fazer a vida inteira trabalho com cabaça. Não é não? Não é? (SAPIEZINSKAS, 2008, p. 224).

Discutir os conceitos e os significados que estão presentes no processo de identificação do trabalho artesanal, para classificar e assim poder definir quem pertence e quem não pertence a esse campo, nos leva a ingressar, necessariamente, num universo de representações. Ana Maria retoma o par "matéria-prima + técnica", sempre presente, e acrescenta o "acabamento" às características que estão em debate na definição do "Artesanato". Em seguida nos brinda com a imagem do "artesanato indígena". Este figura no discurso como síntese daquilo que é "bem natural", ao mesmo tempo em que é questionado: "você não vai ter que fazer a vida inteira trabalho com cabaça". Percebe-se que o discurso da funcionária oscila entre expressão da autoridade, detentora do poder de definir os termos e as categorias, ao mesmo tempo em que ela se afasta desse poder apelando para a instituição que está por trás, quando afirma que ela mesma aceitaria bijuterias feitas de resina: "A Ana Maria acha que é", mas isso não basta, fica subentendido. Sua opinião individual não seria suficiente para modificar as práticas institucionais que foram se estabelecendo.

A classificação burocrática vai se revelando negociada a cada momento, por meio dos procedimentos práticos e das estratégias discursivas que os atores empregam no cotidiano para a manutenção daqueles significados que lhes são mais interessantes. Procuro chamar a atenção para esses processos em que comumente não se percebe o poder de agência do sujeito, como se o burocrata não tivessem nenhum papel ativo a desempenhar, e seus atos fossem destituídos de significado motivado.

Ao mesmo tempo, nessa pequena manipulação do significado corrente, em uso, podemos constatar que a imposição de um conhecimento é um exercício de poder, do poder de quem possui o conhecimento sujeitando aquele que não o possui. A apropriação desse conhecimento e os diferentes usos que dele se faz, quer em proveito e beneficio próprio, quer em nome da instituição, num sentido mais amplo, mostram diferentes ângulos de uma interação entre os atores desse campo, que se relacionam e realizam suas trocas, sendo cada um deles parte das diferentes expressões do poder de agência individual, no âmbito das dinâmicas de poder que se atualizam por meio da linguagem. $O$ conceito de interação social que ora se apresenta nos remete ao interacionismo simbólico, de Erving Goffman (1986), que compartilha de uma noção de realidade social construída através da vivência ou experiência dos atores no contexto vivido. Para este autor, a realidade social não está dada, mas é construída e atualizada no contexto de interação do homem com o seu meio social.

A "interação entre os participantes" é indispensável para a obtenção da "carteirinha de artesão". Para fazer jus ao documento, é preciso fazer uma inscrição, comparecendo ao setor de Artesanato da Secretaria do Trabalho no primeiro dia útil de cada mês, munido de documentos de identificação e do seu material de trabalho artesanal, para mostrar ao vivo como é feito o trabalho. 
Logo na saída do elevador, no andar da Secretaria do Trabalho, é colocada uma pequena mesa de escritório, onde as pessoas que buscam a carteira de artesão preenchem uma ficha prévia de atendimento, mostram seus documentos e falam de suas técnicas. Ali é feita uma triagem dos artesãos e são definidos aqueles que atendem aos requisitos estabelecidos pelo GDF.

Na parede estão afixados cartazes, um deles definindo o conceito de artesanato. Ali encontrei uma definição da prática que leva em conta claramente o tipo de matéria prima empregada, mantendo uma relação estreita com o uso de produtos naturais, além de outras três características básicas, cada uma mais difícil de ser exemplificada na prática do que a outra. O cartaz afirmava também que o artesanato possui valor cultural agregado, criatividade, e outras coisas mais, dispostos ali com clareza e simplicidade, na melhor das intenções para informar o visitante.

\section{GERÊNCIA DE FOMENTO AO ARTESANATO - GFA/GDF}

O ARTESANATO

- Usa matéria prima natural (Ex: barro, couro, fibras, sementes, osso, cordão natural);

- Tem valor cultural agregado;

- Apresenta maior criatividade;

- Não é produzido em série;

- Usa pouco maquinário (30\%) (SAPIEZINSKAS, 2008, p. 230).

Os funcionários da Gerência de Fomento ao Artesanato do GDF preparam cartazes com definições conceituais de artesanato que fazem parecer tratar-se de tema simples, de fácil definição. Nas entrevistas que se seguiram, entretanto, o aprofundamento do assunto levou à exposição da complexidade dessas definições. As conversas, reflexões e tentativas de elucidação, com nuances de significado difíceis de serem definidas, permitiram observar a difícil tarefa burocrática de definição de parâmetros classificatórios, construídos ao mesmo tempo que improvisados, e a discreta possibilidade de manejo das categorias classificatórias, de acordo com o entendimento motivado dos atores sociais, conforme demonstro em seguida.

Na sala de espera, são colocadas cerca de trinta cadeiras, para os candidatos a artesão esperarem a sua vez de demonstrar as técnicas. A sala de espera localiza-se na entrada, saindo do elevador, no corredor de acesso às demais salas. Dali os artesãos são chamadas pelo seu primeiro nome para entrarem numa segunda sala, da Gerência de Fomento ao Artesanato. Atrás da mesa de triagem encontrei Maria Geoni de Oliveira, responsável pelo setor. Ela mesma conversava com as pessoas e indicava quem atenderia aos requisitos, mandando alguns artesãos de volta para casa. Naturalmente, os que são dispensados não encaram isso com muita tranqüilidade, o que resulta em brigas e intensas discussões no local.

Maria Geoni de Oliveira fazia algumas perguntas aos artesãos que se apresentavam ali em busca da carteirinha. Uma resposta errada era suficiente para barrar ali mesmo a oficialização da nova profissão. A funcionária tinha uma ficha na mão, com as exigências estabelecidas pela gerência de fomento ao artesanato da Secretaria do Trabalho do DGF para a concessão da carteira. Primeiro, apresentar documentos de identificação e comprovante de endereço. Segundo, apresentar um objeto pronto para mostrar o resultado final do seu trabalho. Terceiro, empregar alguma das técnicas de artesanato previstas e ainda utilizar matéria-prima natural ou reciclada. Para conseguir encaminhar a carteirinha, era preciso ainda que o artesão se enquadrasse nas categorias de tipos de artesanato, incluindo técnicas e materiais, que foram estabelecidos no setor. Também era preciso demonstrar sua competência artesanal na frente dos técnicos do governo, fazendo artesanato ali mesmo, durante algum tempo, para que pudessem ser avaliados. Caso não atendessem às exigências, não seriam considerados artesãos e não poderiam beneficiar-se das leis de isenção fiscal. 
Segundo Erving Goffman (1986), a sociedade estabelece as categorias a partir das quais classifica os indivíduos e também define o conjunto de atributos que eles têm de preencher para fazer parte delas. As interações sociais seriam baseadas em tais categorias e no conjunto das expectativas dos atores sociais sobre os atributos dos indivíduos que se encaixam nelas.

Presenciei uma curiosa discussão, na mesa de triagem, sobre o emprego correto da técnica de craquelê sobre caixas de madeira. Trata-se de uma técnica que consiste na aplicação de desenhos com algum tipo de resina como cobertura, que resulta num efeito de envelhecimento, ficando a ilustração com aparência quebradiça. Na opinião da técnica da gerência de fomento ao artesanato, o objeto em questão era apenas uma "colagem", o que não se enquadraria em nenhuma das categorias. Entretanto, a artesã garantia que seu produto era um tipo de craquelê. Segundo ela, esse poderia resultar um pouco mais ou um pouco menos quebradiço, e aquele estava um pouco menos, o que não significava que não fosse craquelê.

Irritada com o questionamento de sua prática, não se dispôs a fazer um outro craquelê mais quebradiço, como queria a responsável técnica. Essa, por sua vez, afirmava apenas que aquilo não era craquelê, era colagem, e colagem não qualificaria como artesanato. Não houve diálogo entre as duas, e minha presença não gerou qualquer constrangimento para a troca de ofensas e xingamentos mútuos. Resultou que a artesã foi embora com seu material e sem carteirinha, gritando que "não prestava pra nada mesmo a inútil carteira".

Conversei com ela antes que entrasse no elevador, e a artesã me confidenciou, com certo orgulho, que seus parentes vendiam artesanato, todos sem qualquer carteirinha, e que portanto ela continuaria fazendo o seu craquelê como sempre fizera. Ela dizia não precisar mesmo daquela "burocracia inútil". Entretanto, ainda que inútil, a artesã em questão havia acordado cedo e saído de casa munida de suas artes para apresentar seu trabalho à Gerência de artesanato buscando obter o documento.
Logo em seguida, Maria Geoni me explicou tranquilamente que era necessário estabelecer critérios técnicos para o bom funcionamento daquela gerência e as pessoas não compreendiam que ela estava apenas fazendo cumprir as normas. Os artesãos tinham que cumprir as regras e fazer o trabalho dentro dos requisitos do artesanato, senão tudo poderia virar uma bagunça, onde cada um faria o que desejasse. Aqui se percebe claramente que a funcionária se vê investida de um papel, típico da burocracia, de instaurar ordem em meio ao caos.

Conforme os candidatos mostrassem-se mais dispostos a se encaixar nas normas, a aceitar essa ordem, percebi que contavam com maior colaboração da funcionária. Na lógica da interação, são mais bem sucedidos aqueles que conseguem perceber as regras implícitas ao contexto social e agir em conformidade a elas.

O diálogo que se seguiu - entre a funcionária e uma moça que se apresentou com o que ela chamou de "bijuterias" (pulseiras e colares de contas coloridas, de plástico) - ilustra bem essa dinâmica:

- 'Não', explicou Maria Geoni, 'não pode ser com esse material. Tem que usar coisas naturais, sementes'.

- 'Mas como eu faço então?' quis saber a moça.

- 'Vai ali embaixo, logo em frente tem uma loja de produtos para artesanato, eles vendem miçangas de madeira e sementes. Compra ali um pacotinho pra você poder fazer as suas pulseiras. Depois você volta aqui de novo' (SAPIEZINSKAS, 2008, p. 233).

A grande sala da Gerência de Fomento ao Artesanato estava transformada no dia de visita dos artesãos. As mesas dos burocratas estavam vazias, muitas cadeiras fora do lugar, e tudo tomado por artesãos demonstrando suas técnicas. Gente por todo lado, e os funcionários do setor com pranchetas na mão, preenchendo fichas de avaliação dos trabalhos que observavam. As fichas continham basicamente os campos para dados pessoais e de contatos, 
bem como as categorias previstas na Secretaria para enquadrar os artesãos nas técnicas e materiais, além de um campo para avaliação do grau de competência do artesão. Os funcionários observavam durante algum tempo os artesãos e anotavam ali se a técnica era bem empregada e se o resultado final era ótimo, bom, regular ou satisfatório.

Ana Maria França, que também era a responsável pela elaboração dos parâmetros de cadastramento, explicou o funcionamento daquela gerência. Segundo ela, é muito importante a avaliação do trabalho feita pelos funcionários da Secretaria, pois somente aqueles artesãos que se destacassem mais, que tivessem produtos com acabamento superior, seriam depois convidados a participar de eventos promovidos pela Secretaria do Trabalho. Alguns dos critérios de destaque do trabalho artesanal seriam a criatividade e a originalidade do trabalho. Interessada na subjetividade dessa avaliação, que viria a interferir posteriormente nas oportunidades de comercialização do artesanato, indaguei: “Como é que se diferencia a criatividade da originalidade?". A funcionária, então, respondeu-me:

Eu coloco como originalidade aquilo que a gente custa ver, que é mais difícil, que não é corriqueiro, eu coloco assim. Porque você sabe que bordar todo mundo borda, crochê todo mundo faz, né? Mas tem umas peças aqui que você diria que são originais, elas já tem assim, sabe, fazem esses boleros, que estão usando agora, cada um diferente do outro. Então ela é original e uma técnica que é comum, que é o crochê, que é o tricot, que é o tear (SAPIEZINSKAS, 2008, p. 234).

Ela relacionou as técnicas tradicionais, que seriam algo bem comum, com a moda, sendo a moda aquilo que todo mundo estaria usando e querendo usar. A originalidade estaria, portanto, na combinação inesperada dos elementos. E a criatividade?

A criatividade, é difícil para você poder colocar. Você pode ser criativo e pode ser original. Você pode ser criativo e não ser original. Você pode, você pode ter uma criatividade, e não ter uma originalidade tão grande, ta dentro do comum.
Tem a menina lá que bordou, eu vou dar um exemplo, os bordados. Quais são os bordados que são mais bonitos agora? (...) Customizar, de acordo com a língua, que é francesa e tudo, era mudar, era mudar o costume de acordo com a característica do indivíduo. Então era operar, se você tem um cinto preto e você passa uma tinta dourada, você customizou ele. E, para mim, individualizou, colocou de acordo com ela. Então ela mudou todo o conceito que eu tinha de customizar, e é o conceito que está sendo colocado à população, então, mudou. 0 que está sendo de bordado, o que tenho visto, que tenho gostado, que as pessoas tem gostado mais, é quando eles colocam, uma rendinha, uma fitinha, além aí borda um pouquinho, fica um negócio assim, diferente. Mas isso aqui, é a pessoa criativa, dentro do bordado dela, tem cada bordado, tem uma peça que eu comprei muito criativa, mas não é mais original. Aquele tipo de trabalho, já tem muita gente fazendo. Não vou dizer que não todos, mas tem muita gente fazendo. Aí o que que acontece? Vendo pela mesma linha de trabalho, tem gente fazendo, mas com rococó, fica mais criativo. Nessa linha, mas ele já está criando dentro. Então eu ponho a criatividade nesses termos (SAPIEZINSKAS, 2008, p. 234),

$\mathrm{Na}$ tentativa de esclarecer-me os procedimentos, a funcionária recorreu a exemplos, que acabaram contribuindo para aumentar a confusão sobre a aplicação dos parâmetros. Naturalmente, uma avaliação subjetiva da criatividade e da originalidade dos trabalhos artesanais é difícil de ser explicada. Foi isso o que ficou subentendido, após as longas explicações, nas quais ela jamais afirmaria que se tratava de uma avaliação subjetiva, efetuada por um funcionário, de acordo com sua opinião pessoal, experiência e gosto estético, numa ficha de avaliação estruturada em termos de sim ou não.

Ana Maria França seguia descrevendo os procedimentos burocráticos efetuados durante o registro dos artesãos e procurava explicar como são entendidos pelos funcionários os termos encontrados nos cartazes e nos formulários. A funcionária procurava me fornecer a versão corrente do significado dos termos empregados e informar qual a interpretação que costumam adotar: 
A gente coloca aqui, prioriza bem a matéria prima mais natural possível, sendo que o natural hoje em dia não se pega da natureza, não é? Compra-se muito, se compra semente, tem acesso a semente, e tudo. Mas o que a gente considera, por que também nós estamos dentro de uma Subsecretaria de Ocupação e Renda, a gente considera o artesanato uma boa ocupação, ela é uma ocupação que já vem crescendo o tempo inteiro. Está sendo crescente. Então, o que o artesão vem aqui? Ele vem com a matéria prima dele, ele traz a matéria prima, ele traz o produto pronto, para a gente poder ter noção do todo que ele fez, do acabamento (SAPIEZINSKAS, 2008, p. 240).

A funcionária esclareceu os motivos pelos quais seria necessário submeter os artesãos à observação dos técnicos: para que possam "ter noção do todo que ele fez", ou seja, para que possam avaliar se o resultado final se qualifica como produto artesanal, respeitando inicialmente a regra da apropriação da matéria prima "natural". Se a orientação oficial recomenda o uso de matéria prima natural, ela pondera que "o natural hoje em dia não se pega da natureza, não é? Compra-se...". Portanto, concluo, não existirá defeito se o artesão comprar as sementes na loja da esquina, desde que se trate de matéria prima "natural", e ele demonstre saber empregar as técnicas "apropriadas" para o trabalho com as sementes, conforme o exemplo. Pouco importaria se as sementes pudessem ser adquiridas na mesma loja que vende as contas de plástico, e se a técnica empregada com os dois materiais fosse rigorosamente a mesma, o fato é que "semente" encaixa-se na definição de "matéria prima natural" e portanto qualifica a prática como artesanato, o mesmo não podendo se dizer do plástico. Não parece ocorrer aos funcionários que a artesã, devidamente reconhecida e munida de sua "carteirinha" recém conquistada, provavelmente sairá dali para fazer e vender a bijuteria com miçangas de plástico que sempre produziu, uma vez que as regras da Secretaria não necessariamente serão aplicadas em outros contextos.

O caráter arbitrário da aplicação dos parâmetros definidos pela Secretaria não esconde o fato de que o conceito de "artesanato" se situa no âmbito de um conjunto de representações em que esse fazer, tido como "tradicional", só pode ser efetivamente tradicional, e portanto autêntico, se produzido com "matérias primas naturais". A artesã, no entanto, não necessariamente comunga dessas representações, o que faz com que a interação com a funcionária não represente verdadeira comunicação, entendida como compartilhamento semiótico e contextual.

Observa-se que, em última análise, como a gerência vincula-se a uma "Sub-secretaria de Ocupação e Renda", subordinada à Secretaria do Trabalho, o desempenho da atividade artesanal importaria como uma ocupação, limitada por regras e diretrizes, mas ainda assim uma "boa ocupação":

Ele traz a matéria prima para demonstrar a técnica aqui. Então é o que a gente prioriza, é que ele não faça conosco uma revenda, pois ele pode simplesmente trazer um produto e ser outro que faça, então a gente vê ele demonstrando a técnica aqui e conclui com o acabamento que ele já trouxe a peça pronta Assim que é feito o cadastramento. Ele vem, traz a sua matéria prima, traz o seu produto, mais a documentação. Mas a documentação ele demonstra aqui. (SAPIEZINSKAS, 2008, p. 241)

Assim, outra prática a ser evitada com a demonstração, seria o comércio de artesanato produzido por terceiros, ou seja, a revenda. Daí decorre a importância da demonstração presencial da prática artesanal. Em seguida, Ana Maria França procurou me explicar quais são os segmentos de artesanato que eles têm registrado na Secretaria, revelando quais foram as categorias criadas para organizar a atividade artesanal como um todo. Dentro de cada categoria existe uma interpretação do que se enquadra ali, num jogo semiótico que mais parece um quebra-cabeças. A partir das categorias que foram levantadas inicialmente, os funcionários procuram enquadrar todas as propostas de novas práticas artesanais que surgem, sempre no primeiro dia útil de cada mês. 
A mesma coisa com todas as áreas. Em todos os segmentos do artesanato. Seja cerâmica, deixa eu ver se aqui tem já atualizado. É, fora as principais categorias, mas não chega a ser categoria, a bijuteria, já é um produto. Seria mais cerâmica, mas se coloca aqui mais para entendimento das pessoas. Mas as categorias que nós temos são doze. Deixa eu colocar para você quais são: cerâmica, composto químico e natural... (SAPIEZINSKAS, 2008, p. 241).

As "categorias" de classificação com as quais a funcionária está operando a organização do trabalho artesanal se referem ao tipo de material empregado. Exceto no caso da "Bijuteria", que descreveria um produto, conforme ela explica, e não um tipo de material empregado, e portanto não seria uma categoria. Então a "bijuteria" estaria listada no computador de registro do artesanato, mas não seria uma categoria, porque não corresponderia a um tipo específico de material, mas a um produto. Os demais estariam divididos em categorias de materiais, que no total chegariam a doze, a começar pela cerâmica. $\mathrm{O}$ segundo seria o composto químico natural.

O composto químico natural é aquele artesão que utiliza como matéria prima a borracha, o durepox, o gel, a parafina, então nós não arrumamos ainda um nome que fosse bom para colocar, químico, é mais essa parte química mesmo, é o natural, maisena, que faz o biscuit, você está entendendo? Essas massas de biscuit, resina, que é química. Então esse tipo de matéria-prima nós colocamos nessa categoria que a gente ainda está aprimorando e verificando, está sendo feita, pois é uma coisa que muda muito (SAPIEZINSKAS, 2008, p. 242).

A funcionária procurou então me explicar a lógica dessa forma de classificação, que distribui os artesãos em categorias que variam de acordo com o tipo de material empregado, embora os nomes escolhidos para designálas não facilitem muito a apreensão imediata, deixando um grande espaço para a interpretação e o manejo dos significados por parte dos responsáveis.

Eu me perguntava como um composto químico seria ao mesmo tempo natural, mas os exemplos apresentados já permitiam formar uma ideia do tipo de artesanato que estava sendo classificado ali: tinham em comum a técnica de modelagem.

Outro segmento que tem, é outra categoria. Olha, tem cerâmica, composto natural e químico, couro, fibras vegetais e sementes, folhas do cerrado... (SAPIEZINSKAS, 2008, p. 243).

Retomando as categorias ${ }^{3}$, temos: (1) Cerâmica, (2) Composto químico e natural, (3) Couro, (4) Fibras vegetais e sementes, (5) Folhas do cerrado.

A cada segmento de artesanato que é proposto pelos artesãos ao se inscreverem, deveria corresponder uma categoria de classificação para o registro. Alguns materiais são agrupados, como no caso das "fibras vegetais e sementes", outros são separados em categoria à parte, como "folhas do cerrado", por alguma razão que para mim não era óbvia.

A gente coloca como folhas do cerrado mesmo por que é uma característica mais, Brasília é bem cerrado, então a gente colocou essa categoria mais natural, mais separado. Flores do cerrado. As flores do cerrado que a gente verifica que se utiliza em vários tipos de folhas. A moeda, folha carne de vaca, canela de ema, cervejinha, folha de manga, folha de caju, folha de abacate, sabe, mas ainda não tem um estudo detalhado sobre segmentos dessa categoria, a gente está tentando fazer agora para poder ver, inclusive esse projeto daqui mesmo é para poder aprimorar o próprio arquivo que a gente tem. Então está sendo feito isso. Então, flores do cerrado, madeira, metal, pedras, gemas e corais, reciclados (SAPIEZINSKAS, 2008, p. 243).

Mas as categorias continuam: (6) Madeira, (7) Metal, (8) Pedras, gemas e corais (9) Reciclados.

${ }^{3}$ A numeração empregada corresponde à definição das categorias de organização do artesanato A n é interrompida pelo entrevistadora, com o propósito de investigar as representações subjacenárí construções de sentido atribuídas a cada ítem. 
Observo que criaram uma categoria para "materiais reciclados", independentemente do tipo de material empregado. Pergunto: "Aí entra o quê?" - “Acrílico, metal, papel, plástico, vidro." - responde prontamente Ana Maria França. "Interessante, então retalhos de tecido também são aproveitamento e reciclagem de material, devem entrar aqui", suponho.

Não, retalho de tecido nem tanto, por que você pode comprar o tecido e não aproveitar as sobras, não a sucata mesmo, aquilo que é, até a própria madeira de demolição pode ser reciclada (SAPIEZINSKAS, 2008, p. 244).

Procuro entender: "madeira de demolição pode ser reciclada", mas nesse caso ela entraria na categoria de reciclados ou na categoria de madeira mesmo, que já havia sido mencionada? Continuo me sentindo confusa com a proposta de classificação do artesanato. A artesã que produzia "bijuteria" com plástico novo não estava fazendo artesanato, mas se, ao invés de comprar o material novo, fizesse uso de plástico reciclado, aí poderia bem fazer jus ao título. A funcionária procura me ajudar ilustrando com exemplos, enquanto segue enumerando as categorias.

Mas entra em madeira. Tem essas diferenças com umas nuances muito sutis que a gente procura lidar, por que o conceito é muito difícil de se encontrar, não é uma coisa fácil. 0 que se coloca aqui, por exemplo, o jornal, o jornal é o mais utilizado em termos de reciclado quando a gente faz aqueles trançados, e rendas, bordados, tecelagem e tecido. Tecido pode ser utilizado alguns retalhos. Não, tecelagem é uma, tecido é outra. Rendas e bordados é uma só. Reciclados, outra. Pedras, gemas e corais, uma. Metal, madeira, flores do cerrado, fibras vegetais e semente, couro, composto químico e cerâmica. Um, dois, três, quatro, cinco, seis, sete, oito, nove, dez, onze, doze (SAPIEZINSKAS, 2008, p. 244).

Continuando: (10) Tecelagem, (11) Tecido, (12) Rendas e bordados.

Essas três últimas categorias encerram a lista de categorias de classificação do trabalho dos artesãos de acordo com os critérios da Secretaria de Trabalho do GDF. Elas mostram uma tentativa de organização burocrática que se encontra em uso nessa instituição, independentemente das dificuldades inerentes a toda tentativa de organização das coisas do mundo em categorias distintas. À primeira vista pode parecer um tanto estranha a lista elaborada, mas isso se deve, acredito, ao ponto de vista que adotamos para observar essa prática. Vistas bem de perto, podem causar algum estranhamento, mas na medida em que essas categorias vão se cristalizando através do seu uso, o estranhamento tende a desaparecer, cedendo lugar ao conforto de que "isso tem sido feito assim há muito tempo".

Talvez alguns ajustes ainda sejam necessários na lista de Ana Maria França, até que ela alcance uma certa organicidade e supere as contradições e sobreposições que verificamos. Entretanto, podemos observar um aparente paradoxo: quanto mais confusa a lista se apresenta, mais próxima do real ela se encontra. Isso porque a funcionária não considerou necessário disfarçar o fato de que a definição das categorias de classificação ainda está em processo de análise, ainda não está totalmente estabelecida, analogamente à cidade de Brasília, que ainda está sendo um pouco construída. Ana Maria França, como burocrata recente, está colocando pensamento no trabalho e buscando encontrar soluções para as novas situações que se apresentam no dia-adia. Alguns artesãos já tem sido barrados, mesmo com essa lista ainda em processo. Uma definição mais consistente das categorias de classificação do artesanato, e consequentemente mais fechada, tenderia a excluir mais pessoas dessa atividade, por não se encaixarem com seus trabalhos criativos dentro dos conceitos pré-estabelecidos.

Sobre o cartaz na entrada daquele andar, contendo definições e conceitos de artesanato, a funcionária esclareceu:

Esses são conceitos que a Secretaria coloca para poder definir, sabe, e que é uma definição mais interna, mais para o trabalho interno e também para poder ficar mais claro para a pessoa, por que a própria legislação de ICMS, ela fala de um artesanato como um todo, então isso aí é mais um trabalho interno. 
Não se faz. Agora existe literatura, inclusive muito interessante, se você quiser dê uma olhada, por que quando eu cheguei aqui, eu tenho pouco tempo aqui, então, para mim, o que eu tinha como artesanato era o seguinte, que era tudo que era feito a mão. 0 que nós temos aqui é só para poder esclarecer mais os artesãos, para eles poderem ficar assim, mais pro trabalho da gente, não pode ser nem oficializado isso como conceito por que ele bate até com a própria legislação. Você entendeu? Por que a legislação não fala em trabalho manual, ela não fala em artesanato, ela faz uma definição de artesanato ampla, bem ampla, (SAPIEZINSKAS, 2008, p. 246).

A funcionária se mostrou preocupada com a literatura sobre artesanato, pesquisando autores de onde poderia obter conceituações do artesanato, que pela sua explicação parece ser algo distinto de trabalhos manuais. Ao mesmo tempo em que as informações servem apenas para esclarecer e informar mais e melhor os artesãos, conforme ela afirma, também orientam as pessoas sobre o que esperar e como proceder na sua tentativa de inscrição e registro naquela secretaria, o que na prática significa dizer que a informação opera como uma regra de avaliação da adequação ou inadequação das práticas artesanais dos candidatos. Na medida em que informa os artesãos, a definição serve como um parâmetro para os procedimentos de burocratas e de interessados, resultando numa regra não oficial de procedimentos e operações. A justificativa desse modo de trabalho é dada com base na experiência anterior, apoiada no uso dos computadores com seus bancos de dados. Dessa vez, a autoridade do falante não remete ao website institucional, mas permanece ligada às novas tecnologias, recorrendo ao "banco de dados", conforme ela explica.

Esse trabalho todinho foi feito com base no próprio banco de dados que nós temos dos artesãos aqui, aí nós fomos fazendo pesquisa, e eu com os estagiários, os estagiários muitos deles já foram embora, mas ficou um trabalho até que interessante. Por que aqui a base do Distrito Federal são essas coisas que nós temos aqui. Eu dividi até em matéria prima, os segmentos, as técnicas, dentro do que tinha aqui, por que como eu te disse, eu cheguei aqui sem saber nada, então tive que estudar muito para poder ter uma noção (SAPIEZINSKAS, 2008, p. 247).
A funcionária percebe que os critérios para a organização da atividade artesanal em Brasília estão sendo definidos naquela Secretaria, que acaba comungando do poder institucional de governo local, que se espalha e chega a outros departamentos da administração de Brasília. "O artesanato feito em Brasília não é somente o que se encontra na Torre de Tevê" ${ }^{4}$, diz ela, referindo-se a um dos pontos turísticos principais da cidade. Os artesãos que se cadastram na Secretaria do Trabalho atuam em feiras e eventos do setor, sem necessariamente estarem ligados à Feira da Torre, que tem uma quantidade de espaços de comercialização limitada. Entretanto, Ana Maria França, mesmo destacando a diferença entre o artesanato feito na Torre de Tevê e os artesãos em geral, que estão sendo cadastrados ali na Secretaria, comenta que a tarefa de definição das categorias válidas como trabalho artesanal cabe a elas, funcionárias, e resulta muitas vezes na necessidade de fiscalização do cumprimento do que está registrado ali, espalhando seu poder de definição dos significados correntes para outras esferas da administração local.

Quando se fala em artesanato, a primeira coisa que se pensa aqui em Brasília é Feira da Torre, não é? Mas a Feira da Torre, eu sempre gosto de colocar que a Feira da Torre ela é estabelecida, aqueles espaços, pela administração de Brasília, e não pela Secretaria de Trabalho. Não, o espaço, a divisão, todo aquele negócio é feito pela administração de Brasília. Quando lá a administração tem alguma dúvida em relação ao produto que está na carteira e o produto que ele está vendendo, ela solicita por meio de uma correspondência oficial, que a Geoni faça uma fiscalização. Aí vai ela, junto com o fiscal, para poder verificar se o artesão está vendendo o que ele cadastrou aqui na Secretaria, e que não há uma revenda. Se ele realmente é artesão, ou ele está pegando de outras pessoas e vendendo, (SAPIEZINSKAS, 2008, p. 248)

4 A Torre de TV encontra-se na região central da cidade, no cruzamento dos eixos norte-sul e leste-oeste. Nesse ponto, realiza-se há muitos anos uma feira de artesanato, que hoje já é fixa. 
Maria Geoni de Oliveira, como autoridade responsável pela Gerência de Fomento ao Artesanato, acaba atuando também na fiscalização do cumprimento das regras que sua gerência se vê na responsabilidade de instaurar, ou seja, acaba atuando também no patrulhamento do artesanato em Brasília.

A partir da análise das interações entre técnicos e artesãos na Secretaria de Trabalho do GDF e das entrevistas realizadas, procurei mostrar como os procedimentos foram sendo inventados com base na necessidade, e se destaca como são recentes e negociados os significados implicados nessa tarefa. Um fenômeno que chama a atenção e aqui pode ser claramente percebido é que a expressão de uma visão de organização, ainda que provisória, proferida pelas pessoas que estão na condição de exercer essa tarefa, investidas desse poder de executar uma definição, acaba por tornar-se uma realidade concreta, que se transforma em procedimento padrão dentro do escritório e rompe até mesmo com esses limites, figurando como referência para todos as outras instâncias ligadas ao artesanato na cidade de Brasília.

Michael Herzfeld (1992), analisando o funcionamento das práticas burocráticas, esclarece que "Formal regulations and day-to-day burocratic practices alike are fully embedded in everyday values; the idea of organizational reason is itself a symbolic construct with powerful ideological appeal." (HERZFELD, 1992, p. 18). Em outras palavras, as regulações formais e as práticas burocráticas cotidianas estão fundadas nos valores atuais, que podem ser depreendidos a partir dos discursos acerca dessas práticas. A ideia de uma organização racional é um "construto simbólico", com um apelo ideológico poderoso. Pode-se dizer que tal construto simbólico existe como uma representação à qual os atores sociais reagem e respondem, e assim passa a ter existência concreta no mundo real.

Se as práticas burocráticas não são tão neutras ou livres de crença como se costuma acreditar, se estão imbuídas dos modelos de pensamento e dos valores compartilhados no dia-a-dia pelas pessoas que atuam, que lidam com elas, membros da sociedade, então a observação de Herzfeld pode nos ajudar a pensar como se poderiam interpretar tais práticas burocráticas.

\section{Considerações finais}

Uma vez que Brasília é uma cidade nova, com muita coisa ainda em construção, uma cidade com imagem de cidade moderna, alimentando as representações de uma identidade brasiliense socialmente compartilhada, que se estende desde a construção até a concretização efetiva e acabada do sonho de JK, pode-se supor uma certa liberdade expressiva na exposição dos modelos burocráticos, que seriam eles também algo ainda em processo de construção, algo inacabados. Essa faceta da burocracia sempre existente, mas nem sempre assumida ou demonstrada, mostra-se particularmente presente nessa cidade, onde as pessoas já possuem uma certa familiaridade com a imagem do canteiro de obras, com novos começos, com os processos de construção.

Pode-se afirmar que o canteiro de obras é parte do imaginário simbólico da cidade de Brasília, como mito de origem, disponível no repertório simbólico dos habitantes, pronto para ser acessado e reatualizado conforme a prática ou o ritual torne necessário. Tal imagem continua figurando no imaginário e pode operar como justificativa para ideias de construção e para familiaridade com o trabalho em processo, que se reinventa e reatualiza no uso, conforme surgem as necessidades práticas.

Retomando as fichas de avaliação do trabalho artesanal, que se encontram em processo de elaboração e aprimoramento, temos que as avaliações seguem seu curso e os artesãos seguem sendo registrados na Secretaria do Trabalho, com critérios ainda um tanto subjetivos, num processo em que todo o conteúdo significativo se mostra passível de ser negociado. 
Observa-se, assim, "how mutable was the meaning of their shared symbols" (HERZFELD, 1992, p. 28).

Em meio a categorias um tanto subjetivas, os artesãos são classificados no sistema da Secretaria do Trabalho, e, conforme as avaliações que recebem dos técnicos que realizam a observação, eles teriam oportunidades futuras, podendo ser convidados para feiras, exposições e para a "vitrine do artesão", que se localiza no CONIC, local de grande circulação de pessoas em Brasília.

As entrevistas com as funcionárias da Gerencia de Fomento ao Artesanato permitem longas reflexões sobre o significado das categorias que estão sendo construídas para classificar todo tipo de trabalho artesanal que surge como proposta. Minhas perguntas levavam a explicações cada vez mais longas e detalhadas sobre o trabalho que estão desenvolvendo, numa sequência dialógica que conduzia a novas indagações e reflexões renovadas sobre o significado das práticas.

Esse diálogo permitiu observar, no momento da interação, o processo de negociação de significados, quando a funcionária tranquilamente me explicava quais eram as orientações que recebiam de acordo com a legislação distrital do artesanato, e a forma como eles estavam interpretando e encaminhando as questões na prática. Os significados que ela me informava eram a tradução de um ponto de equilíbrio encontrado entre a letra da lei, imposta pelo Estado, e a forma como ela é entendida e executada no cotidiano, levando em conta as nuances de sentido e adaptações necessárias ao bom funcionamento do trabalho, sendo esse "bom funcionamento" uma categoria êmica e não um modelo ideal.

Procurei mostrar a apropriação que é feita dos conteúdos culturais transmitidos pelo treinamento e formação, ao observar como isso é utilizado pelos indivíduos em proveito próprio, ou seja, nas manobras de sentido efetuadas a partir daquilo que é apreendido, no uso cotidiano, por meio de uma negociação que visa à imposição de um significado. Procuro analisar a forma como esses recursos são empregados do ponto de vista da ação individual do sujeito, no campo dinâmico e vivo do significado corrente, também chamado de cosmologia ou representação, que subjazem às práticas cotidianas

\section{Referências}

DA MATTA, Roberto. Relativizando: uma introdução à antropologia social. Rio de Janeiro, Rocco, 2000.

DOUGLAS, M. How institutions think. Syracuse: Syracuse University Press, 1986

Thought styles. London: Sage Publications, 1996.

FAIRCLOUGH, Norman. Language and power. London: Longman, 2001.

Analysing discourse: textual analysis for social research. London; New York: Routledge. 2003.

Critical discourse analysis: the critical discourse study of language. London: Longman, 1995.

Discurso e mudança social. Brasília, Editora da UNB, 1990.

GEERTZ, Cliford. A interpretação das culturas. Rio de Janeiro: LTC, 1989.

GOFFMAN, Erving. The presentation of self in everyday life. New York: Doubleday, 1959.

. A representação do eu na vida cotidiana. Petrópolis: Vozes, 1986.

HERZFELD, Michael. The social production of indifference. London and Chicago: University of Chicago Press, 1992.

LEVINE, Donald. Introduction. In: SIMMEL, Georg. On individuality and social forms. Chicago: The University of Chicago Press, 1971 [1908].

SAPIEZINSKAS, Aline. De bonecas, flores e bordados: investigações antropológicas no campo do artesanato em Brasília. 2008. 322 fls. Tese (Doutorado em Antropologia Social) - Universidade de Brasília, Brasília, 2008.

Como se constrói um artesão: negociações de significado e uma cara nova para as coisas da vovó. Revista Horizontes Antropológicos, Porto Alegre, ano 18, n. 38, p. 133-158, jul./dez. 2012. 
SIMMEL, Georg. On individuality and social forms. Chicago: The University of Chicago Press, 1971 [1908].

VAN DIJK, Teun. Discourse and context: a sociocognitive approach. Cambridge: Cambridge University Press, 2011.

_. Discurso e contexto: uma abordagem sociocognitiva. São Paulo: Contexto, 2012.

WEBER, Max. Economia e sociedade. Brasília: Editora da UnB, 1999.

Recebido em 21/10/2015.

Aceito em 04/04/2016 